\title{
The Effect of Social Support on Treatment Adherence in Hypertension in China
}

\author{
Jingjing Pan $\mathbb{D}^{\prime}$ \\ Bin $\mathrm{Hu}^{\prime}$ \\ Lian $\mathrm{Wu}^{2}$ \\ Yarong $\mathrm{Li}^{3}$ \\ 'Department of Pharmacy, Xi'an People's \\ Hospital (Xi'an Fourth Hospital), Xi'an, \\ People's Republic of China; ${ }^{2}$ Department \\ of Ophthalmology, Xi'an People's \\ Hospital (Xi'an Fourth Hospital), Xi'an, \\ People's Republic of China; ${ }^{3}$ Department \\ of Pharmacy, School of Pharmaceutical \\ Sciences, Xi'an Medical University, Xian, \\ People's Republic of China
}

\begin{abstract}
Objective: Treatment nonadherence is a major problem in the management of hypertension. There are many factors influencing the treatment adherence of hypertensive patients. The aim of this study was to examine the effect of social support on the treatment adherence in hypertension in China.

Patients and Methods: A total of 453 patients with hypertension hospitalized in a tertiary hospital in Xi'an, China were invited to participate in this cross-sectional study. Data were collected by "modified Chinese Hill-Bone compliance to high blood pressure therapy scale" and "Chinese Family Support Scale".

Results: It was found that $31.1 \%$ of patients were adherent with their antihypertensive treatments. Gender, duration of antihypertensive drug used, number of antihypertensive drugs used and social support were independently associated with hypertensive treatment adherence. Social support was strongly and positively associated with the hypertensive treatment adherence $(P<0.001$, OR $=0.752,95 \%$ CI: $0.678-0.833)$. Family social support was provided to hypertensive patients mainly through their nuclear family, that is spouses, partner or children. Treatment adherence of hypertensive patients was positively correlated to the three subgroups of social support. It was found that social support provided to patients from social resource $(\mathrm{r}=0.568)$ had greater impact on treatment adherence than that from kinship $(\mathrm{r}=0.364)$ and nuclear family $(\mathrm{r}=0.262)$.

Conclusion: Treatment adherence of patients with hypertension was found to increase positively as their social support increased. In addition to the support given to patients from nuclear family members, other social support especially professional agencies and community organizations should also be promoted and strengthened.
\end{abstract}

Keywords: hypertension, treatment adherence, social support, China

\section{Introduction}

Hypertension (HTN) is considered one of the most significant public health challenges worldwide and leads to risk of cardiovascular disease, ${ }^{1}$ stroke $^{2}$ and kidney failure. ${ }^{3}$ In 2019, the leading risk factor globally for attributable deaths was high systolic blood pressure, which accounted for 10.8 million. ${ }^{4}$ Hypertension is estimated to affect one-third of the world's population by $2025 .^{5}$ The pooled prevalence of hypertension among Chinese adults was $24.3 \%$, the annual increase of prevalence was about $0.29 \%$ nonlinearly before 2004 and approximately $2.45 \%$ per year between 2004 and 2010. ${ }^{6}$ Although the prevalence of hypertension is high and increasing, the treatment and control of hypertension are unacceptably low. A study showed that $23.2 \%$ of the Chinese adults in this research $(451,755$ participants) had HTN, and only $15.3 \%$ had controlled HTN. ${ }^{7}$ 
Adherence is considered as one of the most important reasons in controlling blood pressure (BP). ${ }^{8}$ The World Health Organization (WHO) has defined adherence as

The extent to which a person's behavior-taking medication, following a diet, and/or executing lifestyle changescorresponds with agreed recommendations from a health care provider. ${ }^{9}$

Optimal hypertension treatment adherence has significantly positive association with blood pressure control. ${ }^{10}$ Suboptimal adherence is a well-recognized factor contributing to the poor control of blood pressure. ${ }^{11}$

Factors influencing adherence behaviors with hypertension include patient-related factors, social/economicrelated factors, condition-related factors, and healthcare team-related factors. ${ }^{12,13}$ A study showed that adherence to hypertension treatment was strongly associated with social support provided to patients with hypertension. ${ }^{14}$ The American Psychological Association defines social support as "the provision of assistance or comfort to others, typically to help them cope with biological, psychological, and social stressors. Support may arise from any interpersonal relationship in an individual's social network, involving family members, friends, neighbors, religious institutions, colleagues, caregivers or support groups." Adequate and available social support positively affected treatment and adherence of the patients with hypertension and enabled them to cope with the disease effectively. ${ }^{15,16}$ On the other hand, other investigations indicated social support was not associated with treatment adherence. ${ }^{17,18}$ Inappropriate advice from friends and family members may have unintentional negative influences on adherence and selfmanagement behaviors. ${ }^{19}$ Evidence remains inconsistent for relationships between social support and treatment adherence.

There are several studies investigating the relationship between adherence and social support in China; however, most of them have been conducted with other diseases, like diabetes, depression, cancer, and HIV. ${ }^{20-23}$ Few studies on the relationship between adherence and social support involve hypertension. In the present study, we proceeded to further explore the relationship between social support and treatment adherence among Chinese people with hypertension and to provide new research directions for future investigations of treatment adherence.

\section{Methods}

\section{Participants}

This study was a hospital-based, cross-sectional survey carried out in Xi'an People's Hospital (Xi' an Fourth Hospital) in Xi'an, China between January and May 2021. Patients were included if they met the following criteria: $(1) \geq 18$ years-old, (2) diagnosis of primary hypertension, and (3) undergoing antihypertensive drug therapy. Exclusion criteria for all patients included: (1) severe complications of hypertension (eg, severe heart failure and stroke), (2) could not communicate due to physical or mental problems, and (3) pregnant women. The study was approved by the ethics committee of Xi'an People's Hospital (Xi'an Fourth Hospital) (number: $2,021,256)$. We had obtained written informed consent from all participants. All procedures were performed in accordance with the Declaration of Helsinki and relevant policies in China. Investigators explained the goal of this study and gave the standardized instructions before they distributed questionnaires to patients. The patients were asked to complete the questionnaires independently. For relatively illiterate patients, the questions were read by investigators to facilitate questionnaire complication. The minimum sample size was calculated using the formula: $s=z^{2}[p(1-p)] / d^{2}{ }^{24}$ where $\mathrm{s}$ is the minimum sample size, $\mathrm{z}$ is the standard normal variate, $p$ is an estimate of treatment adherence of the patients and $\mathrm{d}$ is the sample error to be tolerated. The confidence interval is $5 \%$; therefore, $\mathrm{d}$ is $0.05, \mathrm{z}$ is 1.96 , and $\mathrm{p}$ was $35.23 \%$ from previous study. ${ }^{13}$ Then, $s=1.962[35.23 \%$ ( $1-$ $35.23 \%)] / 0.052=350.64$. As a result, the minimum sample size required was 351 . Considering the possibility of loss to follow-up, $10 \%$ more samples were added. Thus, the minimum sample size was 387. Finally, 453 patients were recruited in the study as shown in Figure 1.

\section{Measurements}

\section{Demographic Information and Clinical Characteristics}

Patients' data referring to sociodemographic factors including gender, age, education level, marital status, occupational status, health insurance and part of clinical data including duration of HTN and BP categories were collected by reviewing the electronic medical records. The other sociodemographic factors including living conditions, the number of children and some clinical data including duration of antihypertensive drugs used and medication therapy that could not be obtained from the 


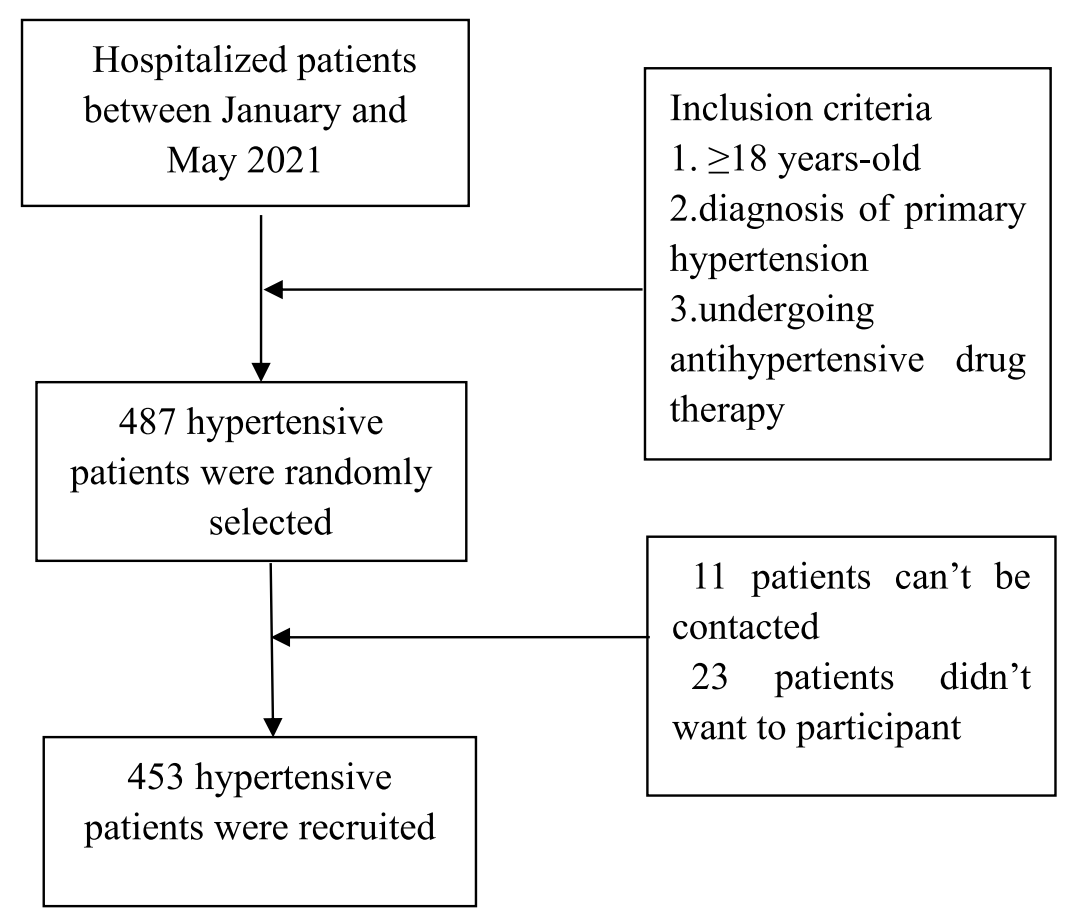

Figure I Flowchart of inclusion of hypertensive patients.

Notes: The patients hospitalized in Xi'an People's Hospital (Xi'an Fourth Hospital) between January and May 2021 were selected according to the inclusion criteria. Four hundred and eighty-seven hypertensive patients were randomly selected, of which II patients cannot be contacted and 23 patients did not want to participate. Finally, 453 hypertensive patients were recruited.

electronic medical records were collected by the investigators through interview.

Controlled hypertension was defined as systolic blood pressure (SBP) $<140 \mathrm{mmHg}$ and/or diastolic blood pressure (DBP) $<90 \mathrm{mmHg}$; Grade I Hypertension was defined as SBP 140-159mmHg and/or DBP 90-99mmHg; Grade II hypertension was defined as SBP $160-179 \mathrm{mmHg}$ and/or DBP 100-109mmHg; Grade III hypertension was defined as $\mathrm{SBP} \geq 180 \mathrm{mmHg}$ and/or DBP $\geq 110 \mathrm{mmHg} .{ }^{25}$ Blood pressure measurement was performed three times by professional doctors using mercury sphygmomanometers. BP was measured in all participants after they were checked to be in the resting state for 10 minutes. The average of three blood pressure values was used in the study.

\section{Treatment Adherence}

The treatment adherence of hypertensive patients was assessed with the Chinese version of the Hill-Bone compliance to high blood pressure therapy scale (HBTS). The 14-items scale was developed by Kim et al in $2000 .{ }^{26}$ It comprises three subscales: medication taking, appointment keeping and reduced sodium intake. Each response ranges from 1 to 4 on Likert scale: none of the times- 4 points, sometimes- 3 points, most of time- 2 points, all the time-1 point. Item scores are summed to produce an overall adherence score of 14 to 56, with higher scores indicating better adherence. A total score of $\geq 80 \%$ was considered as adherence and $<80 \%$ was considered as nonadherence. ${ }^{27-30}$ Percent adherence was calculated using the formula \%adherence $=\left(\right.$ Hill-bone score-14) $\times 100 / 42 .{ }^{29}$ Fourteen is the minimum score, and 42 is the range of scores (56-14). A score $\geq 48$ is considered as adherence and a score $<48$ is considered as non-adherence.

Cronbach's alpha coefficient of HBTS was found to be between 0.74 and 0.84 . Chinese validity and reliability of the scale were analyzed by our team. The Cronbach's alpha score for the entire questionnaire was 0.857 . The modified Chinese Hill-Bone scale had been proved to be a valid and reliable instrument for measuring adherence among Chinese with hypertension. ${ }^{31}$

\section{Social Support}

The Chinese Family Support Scale (CFSS) was used in the present study. The CFSS is a 12-item self-reported instrument with a five-point scale that measures perceptions of family social support from nuclear family, kinship, and social resources. Parents and relatives loaded together on kinship support, spouse or partner and children also loaded together on nuclear family support, and 
professional agencies, community organizations, friends and co-workers together loaded on social resources. Each response ranges from 1 to 5 on Likert scale: not available-1 point, not at all helpful-2 points, sometimes helpful-3 points, generally helpful-4 points, extremely helpful-5 points. Item scores are summed to produce an overall score of 12 to 60 , with higher scores indicating to obtain more social support. This scale had an acceptable internal consistency (Cronbach's alpha $=0.84$ ) and testretest reliability (intraclass correlation coefficient = $0.82) .^{32}$

\section{Statistical Analysis}

Socio-demographic data and clinical characteristics of HTN among the participants were analyzed using descriptive statistics. The univariate analysis of factors for treatment adherence was conducted by using Chi-square test. Binary logistic regression analysis was used to analyze independent risk factor for participants' treatment adherence. Spearman correlation was used to analyze the relationship between HBTS and CFSS and their three dimensions. $P<0.05$ was considered to be statistically significant. All statistical analyses were performed using SPSS version 19 (IBM Corp., Armonk, NY, USA).

\section{Results}

Of the 453 participants, 232 (51.21\%) were female, and 159 (35.10\%) patients were from rural areas (Table 1). Most participants $(89.40 \%)$ were more than 50 years old. Most of the participants (91.17\%) lived with family, and 179 participants $(39.51 \%)$ had no or only one child. Almost half of the patients $(49.45 \%)$ were diagnosed with HTN in the last 10 years. A total of 294 patients $(64.90 \%)$ had been prescribed 1 anti-HTN medication every day. About 37.09\% of the participants had been prescribed antihypertensive drugs for less than 5 years and $40.84 \%$ of them had been prescribed antihypertensive drugs more than 10 years.

Among the 453 participants, 31.1\% had optimal adherence behaviors. The univariate analysis of factors for treatment adherence is provided in Table 2. A total of ten factors including social support $(P<0.001)$ were significantly associated with adherence.

Table 3 summarizes the result of binary logistic regression analysis. Four factors were identified to be independently associated with antihypertensive treatment adherence; gender ( $P=0.008$ ), duration of antihypertensive drug used $(P=0.021)$, number of antihypertensive drugs used $(P=0.008)$ and social
Table I Sociodemographic and Clinical Characteristics of Hypertension Patients $(n=453)$

\begin{tabular}{|c|c|c|c|}
\hline \multicolumn{2}{|l|}{ Characteristics } & \multirow{2}{*}{$\begin{array}{l}\text { Frequency } \\
\quad \text { (n) }\end{array}$} & \multirow{2}{*}{$\begin{array}{c}\begin{array}{c}\text { Percentage } \\
\text { (\%) }\end{array} \\
10.60 \\
53.20 \\
36.20\end{array}$} \\
\hline Age(years) & $\begin{array}{l}<50 \\
50-69 \\
\geq 70\end{array}$ & & \\
\hline Gender & $\begin{array}{l}\text { Female } \\
\text { Male }\end{array}$ & $\begin{array}{l}232 \\
221\end{array}$ & $\begin{array}{l}51.21 \\
48.79\end{array}$ \\
\hline Residence & $\begin{array}{l}\text { Rural } \\
\text { Urban }\end{array}$ & $\begin{array}{l}159 \\
294\end{array}$ & $\begin{array}{l}35.10 \\
64.90\end{array}$ \\
\hline Education level & $\begin{array}{l}\text { Illiterate } \\
\text { Primary } \\
\text { High school } \\
\text { College/University }\end{array}$ & $\begin{array}{l}17 \\
80 \\
252 \\
104\end{array}$ & $\begin{array}{l}3.75 \\
17.66 \\
55.63 \\
22.96\end{array}$ \\
\hline Living condition & $\begin{array}{l}\text { Live alone } \\
\text { Living with family }\end{array}$ & $\begin{array}{l}40 \\
413\end{array}$ & $\begin{array}{l}8.83 \\
91.17\end{array}$ \\
\hline $\begin{array}{l}\text { Number of } \\
\text { children }\end{array}$ & $\begin{array}{l}\leq 1 \\
2 \text { or } 3 \\
\geq 4\end{array}$ & $\begin{array}{l}179 \\
218 \\
56\end{array}$ & $\begin{array}{l}39.51 \\
48.12 \\
12.36\end{array}$ \\
\hline $\begin{array}{l}\text { Occupation } \\
\text { status }\end{array}$ & $\begin{array}{l}\text { Unemployed } \\
\text { Employed } \\
\text { Retired }\end{array}$ & $\begin{array}{l}138 \\
68 \\
247\end{array}$ & $\begin{array}{l}30.46 \\
15.01 \\
54.53\end{array}$ \\
\hline Health insurance & $\begin{array}{l}\text { Urban medical insurance } \\
\text { Rural medical insurance } \\
\text { No medical insurance }\end{array}$ & $\begin{array}{l}240 \\
95 \\
118\end{array}$ & $\begin{array}{l}52.98 \\
20.97 \\
26.05\end{array}$ \\
\hline BP categories & $\begin{array}{l}\text { Grade I Hypertension } \\
\text { Grade II Hypertension } \\
\text { Grade III Hypertension }\end{array}$ & $\begin{array}{l}29 \\
189 \\
235\end{array}$ & $\begin{array}{l}6.40 \\
41.72 \\
51.88\end{array}$ \\
\hline $\begin{array}{l}\text { Duration of } \\
\text { HTN (years) }\end{array}$ & $\begin{array}{l}<5 \\
5-9 \\
10-19 \\
\geq 20\end{array}$ & $\begin{array}{l}141 \\
83 \\
132 \\
97\end{array}$ & $\begin{array}{l}31.13 \\
18.32 \\
29.14 \\
21.41\end{array}$ \\
\hline $\begin{array}{l}\text { Duration of } \\
\text { antihypertensive } \\
\text { drugs used } \\
\text { (years) }\end{array}$ & $\begin{array}{l}<5 \\
5-9 \\
10-19 \\
\geq 20\end{array}$ & $\begin{array}{l}168 \\
100 \\
127 \\
58\end{array}$ & $\begin{array}{l}37.09 \\
22.08 \\
28.04 \\
12.80\end{array}$ \\
\hline $\begin{array}{l}\text { Number of } \\
\text { antihypertensive } \\
\text { drugs used }\end{array}$ & $\begin{array}{l}1 \\
2 \\
\geq 3\end{array}$ & $\begin{array}{l}294 \\
153 \\
6\end{array}$ & $\begin{array}{l}64.90 \\
33.77 \\
1.32\end{array}$ \\
\hline
\end{tabular}

Abbreviations: BP, blood pressure; HTN, hypertension.

support $(P<0.001)$. Males $(P=0.008$, odds ratio $[\mathrm{OR}]=2.041$, 95\% confidence interval [CI]: 1.210-3.443) were less adherent to their treatment than females. Compared with the time used antihypertensive drugs, the longer time resulted in greater adherence for the HTN patients $(P=0.021, \mathrm{OR}=0.917,95 \%$ CI: $0.851-0.987)$. The same positive result was also shown in the number of antihypertensive drugs. The more number of 
Table 2 Factors Associated with Optimal Adherence $(n=453)$

\begin{tabular}{|c|c|c|c|}
\hline Variables & $\begin{array}{l}\text { Adherence } \\
\text { n(\%) }\end{array}$ & $\begin{array}{l}\text { Non } \\
\text { Adherence } \\
\text { n(\%) }\end{array}$ & $P$-value \\
\hline Age(years) & & & $<0.001$ \\
\hline$<50$ & $2(4.17)$ & $46(95.83)$ & \\
\hline $50-69$ & $56(23.24)$ & $185(76.76)$ & \\
\hline$\geq 70$ & $83(50.61)$ & 81 (49.39) & \\
\hline Gender & & & 0.001 \\
\hline Female & $88(37.93)$ & 144 (62.07) & \\
\hline Male & $53(23.98)$ & $168(76.02)$ & \\
\hline Residence & & & $<0.001$ \\
\hline Rural & $33(20.75)$ & $126(79.25)$ & \\
\hline Urban & $108(36.73)$ & $186(63.27)$ & \\
\hline Education level & & & 0.175 \\
\hline Illiterate & $9(52.94)$ & $8(47.06)$ & \\
\hline Primary & $28(35.00)$ & $52(65.00)$ & \\
\hline High school & $74(29.37)$ & $178(70.63)$ & \\
\hline College/University & $30(28.85)$ & $74(71.15)$ & \\
\hline Living condition & & & 0.104 \\
\hline Live alone & $17(42.50)$ & $23(57.50)$ & \\
\hline Living with family & $124(30.02)$ & $289(69.98)$ & \\
\hline Number of children & & & $<0.001$ \\
\hline$\leq 1$ & $41(22.91)$ & 138 (77.09) & \\
\hline 2 or 3 & 71 (32.57) & $147(67.43)$ & \\
\hline$\geq 4$ & $29(51.79)$ & $27(48.21)$ & \\
\hline Occupation status & & & $<0.001$ \\
\hline Unemployed & $29(21.01)$ & 109 (78.99) & \\
\hline Employed & $9(13.24)$ & $59(86.76)$ & \\
\hline Retired & $103(41.70)$ & $144(58.30)$ & \\
\hline Health insurance & & & 0.014 \\
\hline Urban medical insurance & $89(37.08)$ & $151(62.92)$ & \\
\hline Rural medical insurance & $24(25.26)$ & 71 (74.74) & \\
\hline No medical insurance & $28(23.73)$ & $90(76.27)$ & \\
\hline BP categories & & & 0.064 \\
\hline Grade I Hypertension & $5(17.24)$ & $24(82.76)$ & \\
\hline Grade II Hypertension & $53(28.04)$ & $136(71.96)$ & \\
\hline Grade III Hypertension & $83(35.32)$ & $152(64.68)$ & \\
\hline Duration of HTN (years) & & & $<0.001$ \\
\hline$<5$ & $26(18.44)$ & II5 (8I.56) & \\
\hline $5-9$ & $18(21.69)$ & $65(78.31)$ & \\
\hline $10-19$ & $50(37.88)$ & $82(62.12)$ & \\
\hline$\geq 20$ & $47(48.45)$ & $50(51.55)$ & \\
\hline $\begin{array}{l}\text { Duration of antihypertensive } \\
\text { drugs used (years) }\end{array}$ & & & $<0.001$ \\
\hline$<5$ & $31(18.45)$ & $137(81.55)$ & \\
\hline $5-9$ & $27(27.00)$ & $73(73.00)$ & \\
\hline $10-19$ & $49(38.58)$ & $78(6 I .42)$ & \\
\hline$\geq 20$ & $34(58.62)$ & $24(41.38)$ & \\
\hline
\end{tabular}

(Continued)
Table 2 (Continued).

\begin{tabular}{|l|l|l|l|}
\hline Variables & $\begin{array}{l}\text { Adherence } \\
\mathbf{n}(\%)\end{array}$ & $\begin{array}{l}\text { Non } \\
\text { Adherence } \\
\mathbf{n ( \% )}\end{array}$ & P-value \\
\hline $\begin{array}{l}\text { Number of antihypertensive } \\
\text { drugs used }\end{array}$ & $\begin{array}{l}62(21.09) \\
\text { I }\end{array}$ & $\begin{array}{l}232(78.91) \\
78(49.02)\end{array}$ & $<0.001$ \\
2 & $4(66.67)$ & $2(33.33)$ & \\
$\geq 3$ & $37.26 \pm 2.39$ & $33.64 \pm 3.78$ & $<0.001$ \\
\hline $\begin{array}{l}\text { Social support total score } \\
\text { (mean, SD) }\end{array}$ & & & \\
\hline
\end{tabular}

Abbreviations: BP, blood pressure; HTN, hypertension; SD, standard deviation; $P$, probability.

antihypertensive drugs participants took resulted in better adherence $(P=0.008, \mathrm{OR}=0.509,95 \%$ CI: $0.310-0.836)$. The more social support the hypertensive patients obtained, the higher their adherence was $(P<0.001, \mathrm{OR}=0.752,95 \%$ CI: 0.678-0.833).

Scale average scores of participants in the study are shown in Table 4. HBTS average score was $44.25 \pm 5.38$, CFSS total average score was $34.77 \pm 3.79$. Average score of social support from kinship was $9.39 \pm 1.68$, from nuclear family was $8.54 \pm 1.85$, and from social resources was $16.83 \pm 2.60$. In the average score of each item (up to 5 points) of CFSS, the average scores of the support from spouse or partner and children were relatively higher; 4.12 \pm 1.45 and $4.38 \pm 0.89$, respectively.

Furthermore, Spearman correlation analysis showed that there was a statistically significant positive correlation between HBTS total score and CFSS total score ( $\mathrm{r}=0.627$, $P<0.001)$. It was showed HBTS total score was positively related to the three subgroups of social support, separately. Among them, it was found that social support provided to patients from social resource $(\mathrm{r}=0.568)$ had greater impact on treatment adherence than that from kinship ( $\mathrm{r}=0.364)$ and nuclear family $(\mathrm{r}=0.262)$. It was also demonstrated that CFSS total score was positively related with the three subgroups of adherence separately, that is reduced sodium intake ( $\mathrm{r}=0.472)$, appointment keeping ( $\mathrm{r}=0.367)$ and medication taking $(\mathrm{r}=0.603)$. In the relationships between different types of social support and each of the adherence subscales, social support from nuclear family was not related with appointment keeping, and social support from social resources was significantly positive correlation with the three subgroups of adherence (Table 5). 
Table 3 Binary Logistic Regression Analysis of Factors Associated with Adherence in Hypertensive Patients

\begin{tabular}{|c|c|c|}
\hline Variables & OR $(95 \% \mathrm{Cl})$ & $P$-value \\
\hline \multicolumn{3}{|l|}{ Gender } \\
\hline Female & 1.000 & - \\
\hline Male & $2.04 I(1.210-3.443)$ & 0.008 \\
\hline Duration of antihypertensive drug used (years) & $0.917(0.85 I-0.987)$ & 0.021 \\
\hline Number of antihypertensive drugs used & $0.509(0.310-0.836)$ & 0.008 \\
\hline Social support & $0.752(0.678-0.833)$ & $<0.001$ \\
\hline
\end{tabular}

Abbreviations: $\mathrm{OR}$, odds ratio; $\mathrm{Cl}$, confidence interval; $P$, probability.

Table 4 Scale Average Scores of Participants

\begin{tabular}{|l|c|c|}
\hline Scales and Subgroups & Obtained Average Score (Mean I SD) & Obtained Minimum and Maximum Values \\
\hline HBTS & $44.25 \pm 5.38$ & $14-56$ \\
CFSS & $34.77 \pm 3.79$ & $12-60$ \\
Kinship & $9.39 \pm 1.68$ & $4-20$ \\
I.Your parents & $1.38 \pm 0.72$ & $1-5$ \\
2.Your spouse or partner's parents & $1.35 \pm 0.66$ & $1-5$ \\
3.Your relatives & $3.40 \pm 0.93$ & $1-5$ \\
4.Your spouse or partner's relatives & $3.30 \pm 0.94$ & $1-5$ \\
Nuclear family & $8.54 \pm 1.85$ & $2-10$ \\
5.Spouse or partner & $4.12 \pm 1.45$ & $1-5$ \\
8.Your children & $4.38 \pm 0.89$ & $1-5$ \\
Social resources & $16.83 \pm 2.60$ & $6-30$ \\
6.Your friends & $2.88 \pm 0.60$ & $1-5$ \\
7.Your spouse or partner's friends & $2.72 \pm 0.58$ & $1-5$ \\
9. Co workers & $2.49 \pm 0.62$ & $1-5$ \\
I0.Community organizations & $2.78 \pm 0.72$ & $1-5$ \\
II.Professional agencies & $3.84 \pm 0.94$ & $1-5$ \\
I2.Other social organizations & $2.13 \pm 0.39$ & $1-5$ \\
\hline
\end{tabular}

Abbreviations: HBTS, hill-bone compliance to high blood pressure therapy scale; CFSS, The Chinese Family Support Scale; SD, standard deviation.

Table 5 Spearman Correlation Analysis Among the HBTS and CFSS and Their Subgroups

\begin{tabular}{|l|c|c|c|c|c|c|c|c|}
\hline \multirow{2}{*}{ Scales } & \multicolumn{2}{|c|}{ HBTS (Total Score) } & \multicolumn{2}{c|}{ Reduced Sodium Intake } & \multicolumn{2}{c|}{ Appointment Keeping } & \multicolumn{2}{c|}{ Medication Taking } \\
\cline { 2 - 8 } & $\mathbf{r}$ & $\boldsymbol{P}$ & $\mathbf{r}$ & $\boldsymbol{P}$ & $\mathbf{r}$ & $\boldsymbol{P}$ & $\mathbf{r}$ & $\boldsymbol{P}$ \\
\hline CFSS (total score) & 0.638 & $<0.00 \mathrm{I}$ & 0.472 & $<0.00 \mathrm{I}$ & 0.367 & $<0.00 \mathrm{I}$ & 0.603 & $<0.00 \mathrm{I}$ \\
Social support from kinship & 0.364 & $<0.00 \mathrm{I}$ & 0.239 & $<0.00 \mathrm{I}$ & 0.184 & $<0.00 \mathrm{I}$ & 0.354 & $<0.00 \mathrm{I}$ \\
Social support from nuclear family & 0.262 & $<0.00 \mathrm{I}$ & 0.237 & $<0.00 \mathrm{I}$ & $0.02 \mathrm{I}$ & $>0.05$ & 0.249 & $<0.00 \mathrm{I}$ \\
Social support from social resources & 0.568 & $<0.00 \mathrm{I}$ & 0.369 & $<0.00 \mathrm{I}$ & $0.4 \mathrm{II}$ & $<0.00 \mathrm{I}$ & 0.529 & $<0.00 \mathrm{I}$ \\
\hline
\end{tabular}

Abbreviations: HBTS, hill-bone compliance to high blood pressure therapy scale; CFSS, The Chinese Family Support Scale; $P$, probability.

\section{Discussion}

The study focused on the influence of social support on the treatment adherence in patients with hypertension. It was revealed that only 141 patients $(31.1 \%)$ adhered to their antihypertensive treatment. It was determined that the treatment adherence with hypertensive patients in China was unsatisfactory. There are other studies with similar findings to our investigation. ${ }^{13,33}$ In the study, there were 4 independent risk factors related to treatment adherence in hypertensive patients: gender, duration of antihypertensive drug used, number of antihypertensive drugs used and social support. 
It was reported that the treatment adherence of females was higher than that of males. This finding was consistent with some previous studies. ${ }^{34}$ This may be due to the fact that males were generally less adherent to lifestyle modification recommendations than females. ${ }^{35}$ The study also found that the longer patients used antihypertensive drugs and the more the number of antihypertensive drugs patients used, the better their treatment adherence was. A study came to the same conclusion. ${ }^{36}$ A possible reason for this is that with the extension of treatment time, patients gradually accept the fact that they are supposed to take their medication every day and habitually accept that this maintains physical functioning. ${ }^{37}$ Another study showed a different conclusion. It was showed that every increase in the number of prescribed antihypertensive drugs was associated with $85 \%$ and $77 \%$ increase in the odds of the nonadherence in the UK and Czech populations, respectively. ${ }^{38}$

Our study focused on the impact of social support on hypertensive treatment adherence. It was showed that treatment adherence of hypertensive patients was found to have strong and positive correlation with their obtained social support in our investigation. The result was consistent with some previous literatures. Turan from Turkey showed that treatment adherence was found to increase positively as the social support of patients with hypertension increased. ${ }^{39}$ Another study showed that perceived emotional support was associated with optimal medication adherence. ${ }^{21}$ While there are also studies showed that social support was not associated with treatment adherence, ${ }^{40}$ our finding showed that as social support increased, treatment adherence also increased in patient with hypertension.

When the three subgroups of the social support scale were evaluated, it was determined that treatment adherence of hypertensive patients had positive correlation with the social support from kinship, nuclear family and social resources, respectively. The support level perceived from spouse or partner $(4.12 \pm 1.45)$ and children $(4.38 \pm 0.89)$ was higher than the support level from other resources, which demonstrated that the participants received social support mainly through their nuclear family, like spouses or partner and children. Although social support provided from nuclear family members played an important role in improving the treatment adherence of patients in some previous studies, ${ }^{21,41}$ it was found in our study that it had weak relationship $(\mathrm{r}=0.262)$ between treatment adherence and social support from nuclear family.
In our study, we found that availability of support from social resources was strongly associated $(\mathrm{r}=0.568)$ with treatment adherence among the hypertensive patients. Furthermore, social support provided from social resources was positively correlated with reduced sodium intake $(r=0.369)$, appointment keeping $(r=0.411)$ and medication taking $(\mathrm{r}=0.529)$. The support provided from social resources like professional agencies or community organizations can help the patients gain professional information and improve adherence. However, it was showed in the study support level perceived from professional agencies (3.84 \pm 0.94$)$ and community organizations $(2.78 \pm 0.72)$ was lower than support from nuclear family members, which indicated that Chinese hypertensive patients were less likely to gain support or to seek help from a social organization. In addition, the social support provided by social organizations like professional agencies, community organizations or some other social organizations was insufficient. The results of the study served to alert social organizations to provide more social support to these hypertensive patients to improve their treatment adherence.

The limitations of this study were that the measurement of treatment adherence and social support were all based on self-reported questionnaires, which may introduce recall bias. The use of chemical adherence testing is preferred method. ${ }^{42,43}$ Moreover, the study results came from Chinese society with strong focus on family; however, the same results may not be found in other societies with less focus on family. In addition, the study did not cover the impacts of different types of supportive behaviors such as the emotional support and material support on the treatment adherence of hypertensive patients. More and deeper studies focus on specific supportive behaviors should be carried out in future studies.

\section{Conclusions}

In our study, almost two-thirds of the hypertensive participants were nonadherent to treatment adherence. Gender, duration of antihypertensive drug used, number of antihypertensive drugs used and social support were found to be the main factors affecting treatment adherence. Treatment adherence of hypertensive patients was found to have strong and positive correlation with their obtained social support. Furthermore, the treatment adherence also had positive correlation with the three categories of social support. It was found that social support provided to patients from social resource had greater impact on 
treatment adherence than that from kinship and nuclear family. Nuclear family members like spouse or partner and children were the main source of the hypertensive patients gaining social support. Other sources to provide social support especially professional agencies and community organizations should also be paid attention and strengthened. Thus, multidimensional social support from family, friends, kinship, communities and medical staff should be provided for Chinese patients with hypertension in order to improve their treatment adherence. These findings propose the necessity for exploring the promotion of social support as a useful instrument in improving the treatment adherence of hypertension patients.

\section{Disclosure}

The authors report no conflicts of interest in this work.

\section{References}

1. Perumareddi P. Prevention of hypertension related to cardiovascular disease. Prim Care. 2019;46(1):27-39. doi:10.1016/j. pop.2018.10.005

2. Cipolla MJ, Liebeskind DS, Chan SL. The importance of comorbidities in ischemic stroke: impact of hypertension on the cerebral circulation. J Cereb Blood Flow Metab. 2018;38(12):2129-2149. doi: $10.1177 / 0271678 \times 18800589$

3. Anupama YJ, Hegde SN, Uma G, Patil M. Hypertension is an important risk determinant for chronic kidney disease: results from a cross-sectional, observational study from a rural population in South India. J Hum Hypertens. 2017;31(5):327-332. doi:10.1038/ jhh.2016.81

4. Murray CJ, Aravkin AY, Zheng P, et al. Global burden of 87 risk factors in 204 countries and territories, 1990-2019: a systematic analysis for the Global Burden of Disease Study 2019. Lancet. 2020;396(10258):1223-1249.

5. Oliveros E, Patel H, Kyung S, et al. Hypertension in older adults: assessment, management, and challenges. Clin Cardiol. 2020;43 (2):99-107. doi:10.1002/clc.23303

6. Bao M, Wang L. The longitudinal trend of hypertension prevalence in Chinese adults from 1959 to 2018: a systematic review and meta-analysis. Ann Palliat Med. 2020;9(5):2485-2497. doi:10.21037/apm-19-377

7. Wang Z, Chen Z, Zhang L, et al. Status of hypertension in china: results from the china hypertension survey, 2012-2015. Circulation. 2018; 137(22):2344-2356. doi:10.1161/ CIRCULATIONAHA.117.032380

8. Gavrilova A, Bandere D, Rutkovska I, et al. Knowledge about disease, medication therapy, and related medication adherence levels among patients with hypertension. Medicina (Kaunas). 2019;55 (11):715.

9. Burkhart PV, Sabaté E. Adherence to long-term therapies: evidence for action. J Nurs Scholarsh. 2003;35(3):207. doi:10.1111/j.15475069.2003.tb00001.x

10. Animut Y, Assefa AT, Lemma DG. Blood pressure control status and associated factors among adult hypertensive patients on outpatient follow-up at University of Gondar Referral Hospital, northwest Ethiopia: a Retrospective Follow-Up Study. Integr Blood Press Control. 2018;11:37-46. doi:10.2147/IBPC.S150628

11. Burnier M. Drug adherence in hypertension. Pharmacol Res. 2017;125(PtB):142-149. doi:10.1016/j.phrs.2017.08.015
12. van der Laan DM, Elders PJM, Boons C, Beckeringh JJ, Nijpels G, Hugtenburg JG. Factors associated with antihypertensive medication non-adherence: a systematic review. J Hum Hypertens. 2017;31 (11):687-694. doi:10.1038/jhh.2017.48

13. Pan J, Lei T, Hu B, Li Q. Post-discharge evaluation of medication adherence and knowledge of hypertension among hypertensive stroke patients in northwestern China. Patient Prefer Adherence. 2017;11:1915-1922. doi:10.2147/PPA.S147605

14. Osamor PE. Social support and management of hypertension in South-West Nigeria. Cardiovasc $J$ Afr. 2015;26(1):29-33. doi:10.5830/CVJA-2014-066

15. Tan ST, Quek RYC, Haldane V, et al. The social determinants of chronic disease management: perspectives of elderly patients with hypertension from low socio-economic background in Singapore. Int J Equity Health. 2019;18(1):1. doi:10.1186/s12939-018-0897-7

16. Ojo OS, Malomo SO, Sogunle PT. Blood pressure (BP) control and perceived family support in patients with essential hypertension seen at a primary care clinic in Western Nigeria. J Family Med Prim Care. 2016;5(3):569-575. doi:10.4103/2249-4863.197284

17. Nyaaba GN, Stronks K, Meeks K, et al. Is social support associated with hypertension control among Ghanaian migrants in Europe and non-migrants in Ghana? The RODAM Study. Intern Emerg Med. 2019;14(6):957-966. doi:10.1007/s11739-019-02075-7

18. Asgari MR, Bouraghi H, Mohammadpour A, Haghighat M, Ghadiri R. The role of psychosocial determinants in predicting adherence to treatment in patient with hypertension. Interv Med Appl Sci. 2019;11(1):8-16.

19. Ding W, Li T, Su Q, Yuan M, Lin A. Integrating factors associated with hypertensive patients' self-management using structural equation modeling: a cross-sectional study in Guangdong, China. Patient Prefer Adherence. 2018;12:2169-2178. doi:10.2147/PPA.S180314

20. Gu L, Wu S, Zhao S, et al. Association of social support and medication adherence in Chinese patients with type 2 diabetes mellitus. Int $J$ Environ Res Public Health. 2017;14(12):1522. doi:10.3390/ijerph14121522

21. Wang J, Zhao X. Family functioning and social support for older patients with depression in an urban area of Shanghai, China. Arch Gerontol Geriatr. 2012;55(3):574-579. doi:10.1016/j.archger.2012.06.011

22. Mao Y, Qiao S, Li X, Zhao Q, Zhou Y, Shen Z. Depression, social support, and adherence to antiretroviral therapy among people living with HIV in Guangxi, China: a Longitudinal Study. AIDS Educ Prev. 2019;31(1):38-50. doi:10.1521/aeap.2019.31.1.38

23. Tao L, Wang M, Zhang X, Du X, Fu L. Exercise adherence in breast cancer patients: a cross-sectional questionnaire survey. Medicine (Baltimore). 2020;99(22):e20427. doi:10.1097/MD.0000000000020427

24. Akoko BM, Fon PN, Ngu RC, Ngu KB. Knowledge of hypertension and compliance with therapy among hypertensive patients in the Bamenda health district of Cameroon: a Cross-sectional Study. Cardiol Ther. 2017;6(1):53-67. doi:10.1007/s40119-016-0079-x

25. Xie K, Bao L, Jiang X, et al. The association of metabolic syndrome components and chronic kidney disease in patients with hypertension. Lipids Health Dis. 2019;18(1):229. doi:10.1186/s12944-019-1121-5

26. Kim MT, Hill MN, Bone LR, Levine DM. Development and testing of the Hill-Bone compliance to high blood pressure therapy scale. Prog Cardiovasc Nurs. 2000;15(3):90-96. doi:10.1111/j.17517117.2000.tb00211.x

27. Mutneja E, Yadav R, Dey AB, Gupta P. Frequency and predictors of compliance among patients taking antihypertensive medicines. Indian Heart J. 2020;72(2):136-139. doi:10.1016/j.ihj.2020.03.008

28. Hashmi SK, Afridi MB, Abbas K, et al. Factors associated with adherence to anti-hypertensive treatment in Pakistan. PLoS One. 2007;2(3):e280. doi:10.1371/journal.pone.0000280

29. Nashilongo MM, Singu B, Kalemeera F, et al. Assessing adherence to antihypertensive therapy in primary health care in Namibia: findings and implications. Cardiovasc Drugs Ther. 2017;31(5-6):565-578. doi:10.1007/s10557-017-6756-8 
30. Mweene M, Banda J, Andrews B, Mweene M, Lakhi S. Factors associated with poor medication adherence in hypertensive patients in Lusaka, Zambia. Med J Zambia. 2010;37(3):252-261.

31. Pan J, Hu B, Wu L, Wang H, Lei T, Liu Z. The translation, reliability and validity of the Chinese version of the Hill-Bone compliance to high blood pressure therapy scale in adults with hypertension. Patient Prefer Adherence. 2020;14:1853-1860. doi:10.2147/PPA.S268031

32. Li G, Hu H, Dong Z, Arao T. Development of the Chinese family support scale in a sample of Chinese patients with hypertension. PLoS One. 2013;8(12):e85682. doi:10.1371/journal.pone.0085682

33. Pan J, Wu L, Wang H, et al. Determinants of hypertension treatment adherence among a Chinese population using the therapeutic adherence scale for hypertensive patients. Medicine (Baltimore). 2019;98 (27):e16116. doi:10.1097/MD.0000000000016116

34. Yassine M, Al-Hajje A, Awada S, et al. Evaluation of medication adherence in Lebanese hypertensive patients. J Epidemiol Glob Health. 2016;6(3):157-167. doi:10.1016/j.jegh.2015.07.002

35. Kim Y, Kong KA. Do hypertensive individuals who are aware of their disease follow lifestyle recommendations better than those who are not aware? PLoS One. 2015;10(8):e0136858. doi:10.1371/journal. pone. 0136858

36. Yue Z, Bin W, Weilin Q, Aifang Y. Effect of medication adherence on blood pressure control and risk factors for antihypertensive medication adherence. J Eval Clin Pract. 2015;21(1):166-172. doi:10.1111/ jep. 12268

37. Wang W, Lau Y, Loo A, Chow A, Thompson DR. Medication adherence and its associated factors among Chinese community-dwelling older adults with hypertension. Heart Lung. 2014;43(4):278-283. doi:10.1016/j.hrtlng.2014.05.001
38. Gupta P, Patel P, Štrauch B, et al. Risk factors for nonadherence to antihypertensive treatment. Hypertension. 2017;69(6):1113-1120. doi:10.1161/HYPERTENSIONAHA.116.08729

39. Turan GB, Aksoy M, Çiftçi B. Effect of social support on the treatment adherence of hypertension patients. J Vasc Nurs. 2019;37 (1):46-51. doi:10.1016/j.jvn.2018.10.005

40. Ladin K, Daniels A, Osani M, Bannuru RR. Is social support associated with post-transplant medication adherence and outcomes? A systematic review and meta-analysis. Transplant Rev (Orlando). 2018;32(1):16-28. doi:10.1016/j.trre.2017.04.001

41. Chandran A, Benning L, Musci RJ, et al. The longitudinal association between social support on HIV medication adherence and healthcare utilization in the women's interagency HIV Study. AIDS Behav. 2019;23(8):2014-2024. doi:10.1007/s10461-018-2308-x

42. Berra E, Azizi M, Capron A, et al. Evaluation of adherence should become an integral part of assessment of patients with apparently treatment-resistant hypertension. Hypertension. 2016;68(2):297-306. doi:10.1161/HYPERTENSIONAHA.116.07464

43. Gupta P, Patel P, Horne R, Buchanan H, Williams B, Tomaszewski M. How to screen for non-adherence to antihypertensive therapy. Curr Hypertens Rep. 2016;18(12):89. doi:10.1007/ s11906-016-0697-7
Patient Preference and Adherence

\section{Publish your work in this journal}

Patient Preference and Adherence is an international, peer-reviewed, open access journal that focusing on the growing importance of patient preference and adherence throughout the therapeutic continuum. Patient satisfaction, acceptability, quality of life, compliance, persistence and their role in developing new therapeutic modalities and compounds to optimize clinical outcomes for existing disease

\section{Dovepress}

states are major areas of interest for the journal. This journal has been accepted for indexing on PubMed Central. The manuscript management system is completely online and includes a very quick and fair peer-review system, which is all easy to use. Visit http:// www.dovepress.com/testimonials.php to read real quotes from published authors. 